\title{
SCIENCE AND ENGINEERING \\ OF \\ COMPOSITE MATERIALS
}

VOLUME 13, NO. 3

TABLE OF CONTENTS

Numerical and Experimental Investigation into Dynamic Delamination Propagation of Axially Impacted Laminated Composite Beams

Zheng Zhang and Farid Taheri

Identification of Layer Elastic Parameters for Angle-ply Laminated Plates and Shells

(Comparison of Numerical and Experimental Results)

Kenji Hosokawa, Kin'ya Matsumoto, and Yasumasa Nakanishi

Stress Analysis of an Adhesively Bonded Functionally Graded Tubular Single Lap Joint

Subjected to an Internal Pressure

M. Kemal Apalak

An Investigation of Thermal Elasto-Plastic Stress Analysis of Laminated Thermoplastic Composites with a Circular Hole under Uniform Temperature Loading

Faruk Sen

Determination of Mechanical Properties of Weft-Knit I I Rib Glass/Epoxy Composites

Mevlüt Tercan

All rights reserved. No part of this publication may be reproduced, stored in a retrieval systems or transmitted in any form or by any means, electronic or mechanical including photocopying, recording or otherwise, without written permission from the publisher 